\title{
Characterization and Comparison of Canine Multipotent Stromal Cells Derived from Liver and Bone Marrow
}

\author{
Ermanno Malagola, ${ }^{1,2,{ }^{*}}$ Michelle Teunissen, ${ }^{1, *}$ Luc J.W. van der Laan, ${ }^{3}$ Monique M.A. Verstegen, ${ }^{3}$ \\ Baukje A. Schotanus, ${ }^{1}$ Frank G. van Steenbeek, ${ }^{1}$ Louis C. Penning, ${ }^{1}$ Monique E. van Wolferen, ${ }^{1}$ \\ Marianna A. Tryfonidou, ${ }^{1, *}$ and Bart Spee, ${ }^{1, *}$
}

Liver-derived multipotent stromal cells (L-MSCs) may prove preferable for treatment strategies of liver diseases, in comparison to the widely studied bone marrow-derived MSCs (BM-MSCs). Canines are a large animal model, in which the pathologies of liver diseases are similar to man. This study further promotes the implementation of canine models in MSC-based treatments of liver diseases. L-MSCs were characterized and compared to BM-MSCs from the same individual. Both cell types demonstrated a spindle-shaped fibroblast-like morphology, possessed the same growth potential, and demonstrated similar immunomodulation gene expression of CD274, PTGS-1, and PTGS-2. Marked differences in cell surface markers, CD105 and CD146, distinguished these two cell populations, and L-MSCs retained a liver-specific imprinting, observed by expression of $C K 18$ and $C K 19$. Finally, both populations differentiated toward the osteogenic and adipogenic lineage; however, L-MSCs failed to differentiate into the chondrogenic lineage. In conclusion, characterization of canine L-MSCs and BM-MSCs demonstrated that the two cell type populations are highly comparable. Although it is still unclear which cell source is preferred for clinical application in liver treatment strategies, this study provides a foundation for future controlled studies with MSC therapy in various liver diseases in dogs before their application in man.

\section{Introduction}

$\mathrm{M}$ ULTIPOTENT STROMAL CELLS (MSCs) or mesenchymal stem cells [1] are considered one of the best eligible sources for cell therapy. Although first described in the bone marrow, later studies demonstrate that MSCs exist in almost every tissue (eg, adipose tissue [2], umbilical cord blood [3], muscle tissue [4], neuronal tissue [5], and more recently liver tissue $[6,7])$. Due to their immunosuppressive and tissue remodeling properties, MSCs are a promising therapeutic tool in a variety of diseases, including liver disease [8].

Currently, the only curative treatment for severe or endstage liver diseases is liver transplantation. However, the shortage of donor livers remains a problem and $20 \%$ of these patients die before receiving a transplant [9]. Alternatives are therefore needed to treat the increasing number of patients with liver diseases. MSC-based therapy has been shown to be safe and decrease mortality in patients with acute types of liver disease [10]. In addition, MSCs may be a potential therapy for improving liver function [11] and prevent allograft rejection [12]; in particular, these cells may have beneficial effects on hepatocyte proliferation, angiogenesis, tissue repair, and immunomodulation [13,14]. Moreover, MSCs synthesize a wide variety of growth factors and cytokines, including VEGF, TGF- $\beta$, TNF- $\alpha$, HGF, and IL-6, which indirectly aid liver regeneration [15].

Liver-derived MSCs (L-MSCs) were recently discovered and isolated from the preservation fluid of human liver grafts and have hepatocyte differentiation potential as well as immunomodulatory effects. These characteristics render these cells preferable for a potential use in treatment strategies of liver diseases [6]. As these cells carry the genetic imprint of liver cells, their contribution to ameliorating liver disease, both immunosuppression and hepatic differentiation, could be greater compared to the widely studied bone marrow-derived MSCs (BM-MSCs).

To investigate the suitability of MSCs for clinical application, a large animal model is required. Canines are generally accepted as a valid large animal model [16] as the manifestation of liver diseases in dogs is similar to man

\footnotetext{
${ }^{1}$ Department of Clinical Sciences of Companion Animals, Faculty of Veterinary Medicine, Utrecht University, Utrecht, the Netherlands. ${ }^{2}$ Department of Visceral and Transplantation Surgery, Swiss Hepato-Pancreato-Biliary Center, University Hospital, Zurich, Switzerland. ${ }^{3}$ Department of Surgery, Erasmus MC-University Medical Center, Rotterdam, the Netherlands.

*These authors contributed equally to this work.
}

(c) Ermanno Malagola et al., 2015; Published by Mary Ann Liebert, Inc. This Open Access article is distributed under the terms of the Creative Commons Attribution Noncommercial License (<http://creativecommons.org/licenses/by-nc/4.0/>) which permits any noncommercial use, distribution, and reproduction in any medium, provided the original author(s) and the source are credited. 
[17-19]. In addition, dogs are recommended as a translational model for various treatment strategies [20-22].

This study was performed to characterize canine L-MSCs and compare them to BM-MSCs to assist the implementation of the canine model in MSC-based treatment of liver diseases. Notably, by using MSCs derived from the liver and bone marrow of the same individual animal, an in-depth comparison between the two MSC sources can be made without potential confounding effects of individual variation. Characterization of the two tissue sources was based on the minimal criteria formulated by the International Society for Cellular Therapy (ISCT [23]); growth rate and antiinflammatory properties were also compared.

\section{Materials and Methods}

\section{Animals}

Livers and crude bone marrow extracts were obtained from 10 healthy dogs, euthanized for unrelated experiments, according to Utrecht University's 3R policy. All experiments were approved by the Ethics Committee of Animal Experimentation of the Utrecht University as required under Dutch legislation. Microscopic abnormalities of the liver were excluded by histopathological examination of formalin-fixed, paraffin-embedded, and hematoxylin/eosin-stained liver sections by a board-certified veterinary pathologist.

\section{Cell sampling and culture}

BM-MSCs were obtained from the diaphysis of the humerus and/or femur. After disinfecting the skin with chlorhexidine (HiBiscrub; Molnlycke Health Care), an incision was made and the diaphysis removed with an oscillating saw. To collect bone marrow, each diaphysis was flushed and curetted with heparinized $\alpha$-minimum essential medium $(\alpha-\mathrm{MEM})$ (Gibco; Life technologies) supplemented with $10 \%$ fetal bovine serum gold (FBS, high performance, 16000-044; Gibco) and 1\% penicillin/streptomycin (PAA Laboratories). Bone marrow was seeded at $100-150 \times 10^{6}$ cells per T175 culture flask (Greiner Bio-One, CELL$\mathrm{STAR}^{\circledR}$ ). After $24 \mathrm{~h}$, nonadherent cells and cell debris were washed with Hanks balanced salt solution (HBSS; Gibco) with $2 \% \mathrm{FBS}$ and further expanded in an expansion medium consisting of $\alpha$-MEM, $10 \%$ FBS, $1 \%$ penicillin/streptomycin, $0.05 \%$ Fungizone (Invitrogen), $0.1 \mathrm{mM}$ ascorbic acid-2phosphate (Sigma), $10^{-9} \mathrm{M}$ dexamethasone (Sigma), and $1 \mathrm{ng} / \mathrm{mL}$ bFGF (AbD Serotec). Cells were incubated at $37^{\circ} \mathrm{C}$ in a humidified atmosphere containing $5 \% \mathrm{CO}_{2}$. On average, cells reached $80 \%$ confluency within 7 days and then were cryopreserved in $\alpha$-MEM, $10 \%$ DMSO, and $10 \%$ FBS. After thawing, cells were seeded at $6 \times 10^{3}$ cells $/ \mathrm{cm}^{2}$ and expanded up to passage 6 , followed by cryopreservation of passages 2 and 4 until further analysis [gene expression profiling and fluorescent-activated cell sorting (FACS) analysis].

L-MSCs were obtained through enzymatic digestion of liver tissue. Livers were excised aseptically from cadavers and wedge biopsies placed in cold HBSS. Immediately after surgical sampling, wedge biopsies were minced and frozen in multiple cryovials (average $1.9 \mathrm{~g}$ of tissue per vial) in Dulbecco's modified Eagle's medium (DMEM)/F12 (Gibco; Life technologies) with $40 \%$ FBS and $10 \%$ DMSO. Frozen samples were thawed at $37^{\circ} \mathrm{C}$ for $5 \mathrm{~min}$ and briefly washed and digested with $50 \mathrm{U} / \mathrm{mL}$ collagenase type II (Worthington) in $\alpha$-MEM for $1 \mathrm{~h}$ in a $37^{\circ} \mathrm{C}$ water bath. Cells then were collected by low-speed centrifugation ( $50 \mathrm{~g}, 10 \mathrm{~min})$, plated in a six-well plate in the expansion medium also used for BM-MSCs, and cultured at $37^{\circ} \mathrm{C}$ under humidified conditions containing $5 \% \mathrm{CO}_{2}$. After $24 \mathrm{~h}$, nonadherent cells and cell debris were washed away with prewarmed HBSS and the expansion medium was added. Medium was changed twice a week and cells passed using trypsin for $5 \mathrm{~min}$ at $37^{\circ} \mathrm{C}$. For each passage, cells were seeded at a density of $6 \times 10^{3}$ cells $/ \mathrm{cm}^{2}$.

\section{Population doubling assay}

A population doubling (PD) assay was performed to establish growth potential; L-MSCs and BM-MSCs were seeded at a density of $\sim 6 \times 10^{3}$ cells $/ \mathrm{cm}^{2}$. Every third day, cells were trypsinized, counted, and seeded again at the same seeding density of $6 \times 10^{3}$ cells $/ \mathrm{cm}^{2}$. A PD estimation was calculated using the following formula (Hayflick): $\mathrm{PD}=\log (\mathrm{Nf})-\log (\mathrm{Ni}) / \log 2$ [24], where PD computes the number of cell divisions that occur in each passage $(\sim 3$ days), Nf corresponds to cell number on the third day, and $\mathrm{Ni}$ is the initial seeding number of cells. The cumulative PD corresponds with the total number of estimated divisions up to that passage.

\section{RNA sampling and analysis}

Total RNA was isolated from L-MSC and BM-MSC cultures at different passages (from passage 0 to 4 ), using an RNeasy Mini Kit (Qiagen) with on-column DNase digestion. RNA quantity was determined using NanoDrop ND1000 (Thermo Fisher Scientific). Pooled RNA, isolated from normal liver tissue and crude bone marrow extract, was used as a reference. After isolation, cDNA was created with the iScript cDNA Synthesis Kit (Bio-Rad). RNA input for each sample was set at $350 \mathrm{ng} / \mu \mathrm{L}$. PerlPrimer v1.1.14 was used for primer design on Ensembl annotated transcripts, and the amplicon was tested for secondary structures using MFold [25]. Gradient polymerase chain reactions (PCRs) were performed to determine the optimum temperature for obtaining 100\% PCR efficiency. Primer specificity was validated in silico (BLAST specificity analysis) and empirically (DNA sequencing and melting profiles). Quantitative PCRs (qPCRs) were performed in duplicate containing iQ SYBR Green Supermix (Bio-Rad), $0.4 \mu \mathrm{M}$ primer, and $4 \mu \mathrm{L}$ of $50 \times$ diluted cDNA. Four reference genes were used for normalization, ribosomal protein S19 (RPS19), ribosomal protein L13 (RPL13), hypoxanthine phosphoribosyltransferase 1 (HPRT), and $\beta$-2-microglobulin (B2MG) [26], and were chosen based on their high stability as established by GeNorm [27]. Primers for reference genes and genes of interest, including optimum temperatures, are listed in Table 1. All experiments were conducted with a C1000 Touch $^{\text {TM }}$ Thermal Cycler (Bio-Rad). Specificity of the amplicons was confirmed with a melt curve analysis at the end of the PCR for each sample, and a 4-fold standard dilution series of a pool containing all samples was used to determine relative expression. Data analysis was performed with CFX Manager ${ }^{\mathrm{TM}}$ software (Bio-Rad), and expression levels 
Table 1. Quantitative PCR Primers Specifics

\begin{tabular}{|c|c|c|c|c|}
\hline Gene & Sequence & Accession number & Amplicon & Temperature $\left({ }^{\circ} \mathrm{C}\right)$ \\
\hline CD105 & $\begin{array}{l}\text { CAT-CCT-TCA-CCA-CCA-AGA-G } \\
\text { CAG-ATT-GCA-GAA-GGA-CGG }\end{array}$ & ENSCAFG00000020106 & 139 & 60 \\
\hline$C D 90$ & $\begin{array}{l}\text { CAG-CAT-GAC-CCG-GGA-GAA-AAA-G } \\
\text { TGG-TGG-TGA-AGC-CGG-ATA-AGT-AGA }\end{array}$ & ENSCAFG00000029265 & 134 & 63.5 \\
\hline CD166 & $\begin{array}{l}\text { AAG-CGT-CAT-AAA-CCA-AAC-AG } \\
\text { TAT-AGC-AGA-GAC-ATT-CAA-GGA-G }\end{array}$ & ENSCAFG00000009721 & 150 & 61 \\
\hline$C D 29$ & $\begin{array}{l}\text { GAT-GCC-TAC-AAC-TCC-CTT-TCC-TCA } \\
\text { CAT-TTT-CCC-CTG-TTC-CAT-TCA-CC }\end{array}$ & ENSCAFT00000006178 & 118 & 60 \\
\hline$C D 73$ & $\begin{array}{l}\text { CTC-CAA-CAC-ATT-CCT-TTA-CAC } \\
\text { ACT-CAA-CCT-TCA-AAT-AGC-CT }\end{array}$ & ENSCAFG00000002994 & 150 & 61 \\
\hline$C D 44$ & $\begin{array}{l}\text { CTT-CTG-CAG-ATC-CGA-ACA-CA } \\
\text { GAG-TAG-AAG-CCG-TTG-GAT-GG }\end{array}$ & ENSCAFG00000006889 & 147 & 60 \\
\hline$C D 45$ & $\begin{array}{l}\text { GAC-CAT-GGG-GTG-CCT-GAA-GAT } \\
\text { CAC-AAT-GGG-GCC-ACT-GAA-GAA-G }\end{array}$ & ENSCAFG00000011265 & 90 & 60 \\
\hline$C D 235 a$ & $\begin{array}{l}\text { AAG-CAG-GTT-TCA-TTT-CCA-CAG- } \\
\text { TCC-CTA-TTA-TCA-CTG-GTT-CAG-AG }\end{array}$ & ENSCAFG00000031944 & 152 & 60 \\
\hline$C D 11 b$ & $\begin{array}{l}\text { ACT-CAG-ACA-GGA-AGT-AGC-A } \\
\text { CAG-CAT-AAC-CCA-AGT-AAG-CA }\end{array}$ & ENSCAFG00000016881 & 210 & 61 \\
\hline$C D 14$ & $\begin{array}{l}\text { CCC-GGC-GCT-CAC-CAC-CTT-AGA-C } \\
\text { CCT-GGA-GGG-CCG-GGA-ACT-TTT-G }\end{array}$ & ENSCAFG00000005852 & 98 & 60 \\
\hline$C D 19$ & $\begin{array}{l}\text { CAA-GAC-CAA-CTC-TCC-CAG } \\
\text { CCT-CAT-TCT-CGT-AAG-ACT-CAG }\end{array}$ & ENSCAFG00000017303 & 111 & 60 \\
\hline$C D 144$ & $\begin{array}{l}\text { GAT-ATT-CCA-TCC-GCA-AGA-CC } \\
\text { AAT-CCA-GTT-CTT-TAG-CCT-CCA }\end{array}$ & ENSCAFG00000020413 & 137 & 61 \\
\hline CK18 & $\begin{array}{l}\text { TTG-CTA-CCT-ACC-GTC-GCC-TGT-TGG } \\
\text { ATC-TTG-CGG-GTG-GTG-GTC-TTC-TGG }\end{array}$ & ENSCAFG00000007154 & 109 & 63.5 \\
\hline CK19 & $\begin{array}{l}\text { GCC-CAG-CTG-AGC-GAT-GTG-C } \\
\text { TGC-TCC-AGC-CGT-GAC-TTG-ATG-T }\end{array}$ & ENSCAFT00000025270 & 86 & 63.5 \\
\hline$A L B$ & $\begin{array}{l}\text { TGT-TCC-TGG-GCA-CGT-TTT-TGT-A } \\
\text { GGC-TTC-ATA-TTC-CTT-GGC-GAG-TCT }\end{array}$ & ENSCAFT00000004843 & 92 & 63.5 \\
\hline ONECUT1 & $\begin{array}{l}\text { ACC-CTG-GAG-CAA-ACT-CAA-GTC } \\
\text { CCT-TCC-CAT-GTT-CTT-GTT-CTT-TCC }\end{array}$ & ENSCAFG00000015867 & 134 & 58 \\
\hline$N A N O G$ & $\begin{array}{l}\text { CAA-GCA-CCC-AAC-TCT-AGG } \\
\text { GTC-CTG-AGT-AAG-CAG-ATC-C }\end{array}$ & ENSCAFG00000031047 & 150 & 64.5 \\
\hline OCT4 & $\begin{array}{l}\text { ACG-ATC-AAG-CAG-TGA-CTA-TTC-G } \\
\text { GAG-GGA-CTG-AGG-AGT-AGA-GCG-T }\end{array}$ & ENSCAFG00000000485 & 158 & 64.5 \\
\hline SOX2 & $\begin{array}{l}\text { AAC-CCC-AAG-ATG-CAC-AAC-TC } \\
\text { CGG-GGC-CGG-TAT-TTA-TAA-TC }\end{array}$ & ENSCAFG00000011642 & 152 & 61 \\
\hline$L G R 5$ & $\begin{array}{l}\text { AGT-CGA-TAC-CGG-AGA-AAG-CA } \\
\text { GAG-GCA-CCG-TTC-AGA-GTC-A }\end{array}$ & ENSCAFG00000000451 & 139 & 61 \\
\hline $\operatorname{LIN} 28$ & $\begin{array}{l}\text { CCA-CCC-CAG-CCC-AAG-AA } \\
\text { CAG-TGG-ACA-CGA-GGC-TAC-CA }\end{array}$ & ENSCAFG00000012488 & 66 & 61 \\
\hline$C D 133$ & $\begin{array}{l}\text { CTG-GGG-CTG-CTC-TTT-GTG-AT } \\
\text { AGG-CCC-CAT-TTT-TCT-TCT-GTC }\end{array}$ & ENSCAFT00000044445 & 115 & 60.5 \\
\hline$C D 74$ & $\begin{array}{l}\text { CTG-CCC-ATT-CAA-AGC-CTG } \\
\text { GTT-CTC-AAA-GAC-CTT-CCA-ATC-C }\end{array}$ & ENSCAFG00000018101 & 197 & 64 \\
\hline$C D 274$ & $\begin{array}{l}\text { CGT-TCC-AGC-AAG-TGA-GAG } \\
\text { CCA-CAT-CCA-TCA-TTC-TCC-C }\end{array}$ & ENSCAFG00000002120 & 115 & 64 \\
\hline PTGS-1 & $\begin{array}{l}\text { GTT-CCT-GTT-CAA-CAC-CTC-C } \\
\text { GTC-TAT-GTT-TCT-ACC-TCC-ACC }\end{array}$ & ENSCAFG00000020263 & 105 & 61 \\
\hline PTGS-2 & $\begin{array}{l}\text { GTA-TGA-GCA-CAG-GAT-TTG-AC } \\
\text { TGA-AGT-GGG-TAA-GTA-TGT-AGT-G }\end{array}$ & ENSCAFG00000013762 & 149 & 60 \\
\hline CD146 & $\begin{array}{l}\text { GGG-AAT-GCT-GAA-GGA-AGG } \\
\text { CTT-GGT-GCT-GAG-GTT-CTG }\end{array}$ & ENSCAFG00000012079 & 99 & 63 \\
\hline RPS19 & $\begin{array}{l}\text { CCT-TCC-TCA-AAA-AGT-CTG-GG } \\
\text { GTT-CTC-ATC-GTA-GGG-AGC-AAG }\end{array}$ & ENSCAFG00000001608 & 95 & 62 \\
\hline$R P L 13$ & $\begin{array}{l}\text { GCC-GGA-AGG-TTG-TAG-TCG-T } \\
\text { GGA-GGA-AGG-CCA-GGT-AAT-TC }\end{array}$ & ENSCAFG00000019840 & 87 & 62 \\
\hline$B 2 M G$ & $\begin{array}{l}\text { TCC-TCA-TCC-TCC-TCG-CT } \\
\text { TTC-TCT-GCT-GGG-TGT-CG }\end{array}$ & ENSCAFG00000013633 & 85 & 62 \\
\hline$H P R T$ & $\begin{array}{l}\text { AGC-TTG-CTG-GTG-AAA-AGG-AC } \\
\text { TTA-TAG-TCA-AGG-GCA-TAT-CC }\end{array}$ & ENSCAFG00000018870 & 104 & 58 \\
\hline
\end{tabular}

PCR, polymerase chain reaction. 
were normalized using the average relative amount of the reference genes.

\section{Differentiation potential, osteogenic differentiation}

For osteogenic differentiation, L-MSCs were plated at 3,000 cells $/ \mathrm{cm}^{2}$ and BM-MSCs at 1,000 cells $/ \mathrm{cm}^{2}$ in 12-well plates (Greiner Bio-One, CELLSTAR). BM-MSCs were seeded at a lower density to prevent cell detachment due to over confluence (occurs after 2 weeks of culture). For 21 days, cells were supplemented with an osteogenic-inducing medium twice a week, consisting of DMEM high glucose (Invitrogen), 10\% FBS, 1\% penicillin/streptomycin, $0.1 \mathrm{mM}$ ascorbic acid, $10^{-7} \mathrm{M}$ dexamethasone, and $10 \mathrm{mM}$ $\beta$-glycerol-phosphate. Control wells were seeded at the same density and received expansion medium for 21 days. After 21 days, duplicates of the osteogenic-differentiated and control wells were collected in $350 \mu \mathrm{L}$ RLT (Qiagen) for RNA analysis as described above. In addition, duplicates of both conditions were stained after fixation, for 30 min at RT with 2\% Alizarin Red, pH 4.1-4.3 (Sigma), for histological and morphological evaluation of calcium deposits. Images were acquired using an Olympus BX60 microscope with a ColorView III digital camera and cell imaging software (Olympus).

\section{Differentiation potential, adipogenic differentiation}

For adipogenic differentiation, cells were plated at 150,000 cells $/ \mathrm{cm}^{2}$ in 12-well plates (Greiner Bio-One, CELLSTAR) and an adipogenic-inducing medium was added when a confluency of $90 \%-100 \%$ was reached. For 21 days, an adipogenic-inducing medium was added [DMEM high glucose, $10 \%$ FBS, $1 \%$ penicillin/streptomycin, $0.1 \mathrm{mM}$ ascorbic acid, $10^{-6} \mathrm{M}$ dexamethasone, $0.2 \mathrm{mM}$ indomethacin (Sigma), $0.5 \mathrm{mM} 1$ methyl-3-isobutyl xanthine (IBMX; Sigma), and $0.1 \mathrm{mg} / \mathrm{mL}$ insulin (Sigma)]. Control wells were seeded at the same density and received expansion medium for 21 days. Medium changes were performed twice a week. After 21 days, duplicate adipogenic-differentiated wells and duplicate control wells were collected for each donor in $350 \mu \mathrm{L}$ RLT for RNA analysis as previously described. In addition, duplicates of both conditions were stained after fixation for $20 \mathrm{~min}$ at RT with $0.3 \%$ Oil Red O (Sigma); lipid droplets were identified with light microscopy (Olympus Bx60 microscope).

\section{Differentiation potential, chondrogenic differentiation}

For chondrogenic differentiation, cells were cultured in a three-dimensional pellet culture: 200,000 cells were suspended in $0.2 \mathrm{~mL}$ of chondrogenic-inducing differentiation medium, consisting of DMEM high glucose, $1 \%$ penicillin/ streptomycin, $1 \%$ ITS+ premix (354352; BD), $0.04 \mathrm{mg} / \mathrm{mL}$ proline (Sigma), $0.1 \mathrm{mM}$ ascorbic acid, $0.1 \mu \mathrm{M}$ dexamethasone, and $10 \mathrm{ng} / \mathrm{mL}$ TGF- $\beta 1$ (240-B-002; R\&D Systems). The pellets of the control group were suspended at the same density in $0.2 \mathrm{~mL}$ of chondrogenic differentiation medium without TGF- $\beta 1$. Initially, L-MSC chondrogenesis was not induced; therefore, in a follow-up experiment, we cultured L-MSC pellets in the presence of TGF- $\beta 1(10 \mathrm{ng} / \mathrm{mL})$ and BMP-2 (250 ng/mL; R\&D). The suspensions were placed in a 96-well round-bottom polystyrene plate (Corning Costar 7007) resulting in ultralow attachment of the cells, which was centrifuged for 5 min at $1,500 \mathrm{rpm}$ at RT. Medium was changed every day for 2 weeks and thereafter every other day for another week. After 21 days, three pellets were collected from every condition for RNA isolation and qPCR analysis and two pellets for histological evaluation. We stained $5 \mu \mathrm{m}$ thick sections with $0.125 \%$ Safranin O (Sigma) for proteoglycans in cartilage and counterstained with $0.4 \%$ Fast Green (Sigma); differentiation status was assessed by staining and morphology of the cell pellet.

\section{Gene expression analysis of differentiated cell populations}

Specific cell lineage tracing primers (Table 2) were selected and designed for each of the differentiation lineages. Genes included in this study were as follows: adipogenic differentiation marker, Adiponectin (ADIPOQ); osteogenic markers, Osteonectin (SPARC), Osteocalcin (BGLAP), and Osteopontin (SPP1); chondrogenic markers, SOX9, Collagen type IIa (COL2 $\alpha 1)$, Aggrecan (ACAN), and Collagen type $X(C O L X)$ [28]. Five reference genes were required for reliable normalization as assessed by GeNorm analysis [27]: ribosomal protein L8 (RPL8), glucuronidase beta (GUSB), ribosomal protein S5 (RPS5), B2MG, succinate dehydrogenase complex, and subunit A (sDHA).

\section{FACS analysis}

Cell fractions were collected during passages 2 and 4 for cell sorting purposes; a minimum of $5 \times 10^{5}$ cells were cryopreserved in $\alpha$-MEM, $40 \%$ FBS, and $10 \%$ DMSO for FACS analysis. Fractions were seeded for 2-3 days in expansion medium before analysis. After culture, cells were trypsinized and counted and a minimum of $50 \times 10^{3}$ to a maximum of $100 \times 10^{3}$ cells per reaction were used for each condition. Cells were washed in phosphate-buffered saline (PBS, pH 7.4) and resuspended in $50 \mu \mathrm{L}$ of FACS buffer (PBS, $10 \%$ FBS, and $0.1 \% \mathrm{w} / \mathrm{v}$ sodium azide). At this point, cells were incubated with the respective antibodies or controls (Table 3 ) for $30 \mathrm{~min}$ on ice and then washed twice with FACS buffer to remove the nonbonded antibody. 7-Aminoactinomycin D (7AAD, $0.25 \mu \mathrm{g} /$ test; BD Biosciences) was added before analysis to select for dead cells. All used antibodies were phycoerythrin (PE) labeled. Data were collected with the FACS Diva software (version 8.0) on a CANTO II (BD Biosciences) and analysis performed with FlowJo software (www.flowjo.com/).

\section{Statistical analyses}

For all statistical analyses, R statistical software 2.15 was used.

Doubling time of L-MSCs and BM-MSCs during the first six passages was analyzed by a linear mixed model, containing fixed and random effects. Parameters chosen as fixed effects consisted of "cell type" (BM-MSC or L-MSC), "donor age" (puppy or adult), and "the passage"; "donor" was added as a random effect. The best fitting model was chosen based on the Akaike information criterion (AIC). Normal distribution of the data was assessed and confirmed by analyzing the QQ plot of the acquired model. Differences were considered to be significant if a difference of zero (no difference) could not be found in the $99 \%$ confidence interval to correct for multiple comparisons. 
Table 2. Quantitative PCR Primers (Differentiation Potential Assessment)

\begin{tabular}{|c|c|c|c|c|}
\hline Gene & Sequence & Accession number & Amplicon & Temperature $\left({ }^{\circ} \mathrm{C}\right)$ \\
\hline \multicolumn{5}{|c|}{ Adipogenic lineage } \\
\hline$A D I P O Q$ & $\begin{array}{l}\text { AGA-GAA-AGG-AGA-TGC-AGG-T } \\
\text { CGA-ACG-GTG-TAC-ATA-GGC }\end{array}$ & NM_001006644 & 141 & 62 \\
\hline \multicolumn{5}{|c|}{ Osteogenic lineage } \\
\hline SPARC & $\begin{array}{l}\text { TCT-GTA-TGA-AAG-GGA-TGA-GGA-C } \\
\text { TCT-GTA-TGA-AAG-GGA-TGA-GGA-C }\end{array}$ & XM_849889 & 82 & 64 \\
\hline$S P P 1$ & $\begin{array}{l}\text { GAA-TGC-TGT-GCT-GAC-TGA-GG } \\
\text { TGG-CTA-TCC-ACA-TCG-TCT-CC }\end{array}$ & XM_003434024 & 113 & $66-67$ \\
\hline BGLAP & $\begin{array}{l}\text { CTGA-TGG-TCC-TTG-CCC-T } \\
\text { CTT-GGA-CAC-GAA-GGT-TGC }\end{array}$ & XM_547536 & 116 & $60-63$ \\
\hline \multicolumn{5}{|c|}{ Chondrogenic lineage } \\
\hline$A C A N$ & $\begin{array}{l}\text { GGA-CAC-TCC-TTG-CAA-TTT-GAG } \\
\text { GTC-ATT-CCA-CTC-TCC-CTT-CTC }\end{array}$ & NM_001113455 & 110 & $60-61$ \\
\hline$C O L 2 \alpha 1$ & $\begin{array}{l}\text { GCA-GCA-AGA-GCA-AGG-AC } \\
\text { TTC-TGA-GAG-CCC-TCG-GT }\end{array}$ & NM_001006951 & 150 & $60.5-65$ \\
\hline SOX9 & $\begin{array}{l}\text { CGC-TCG-CAG-TAC-GAC-TAC-AC } \\
\text { GGG-GTT-CAT-GTA-GGT-GAA-GG }\end{array}$ & NM_001002978 & 105 & $62-63$ \\
\hline COL10 & $\begin{array}{l}\text { CCA-ACA-CCA-AGA-CAC-AG } \\
\text { CAG-GAA-TAC-CTT-GCT-CTC }\end{array}$ & XM_849417 & 80 & 61 \\
\hline \multicolumn{5}{|c|}{ Reference genes } \\
\hline$R P L 8$ & $\begin{array}{l}\text { CCA-TGA-ATC-CTG-TGG-AGC } \\
\text { GTA-GAG-GGT-TTG-CCG-ATG }\end{array}$ & XM_532360 & 64 & 55 \\
\hline GUSB & $\begin{array}{l}\text { AGA-CGC-TTC-CAA-GTA-CCC-C } \\
\text { AGG-TGT-GGT-GTA-GAG-GAG-CAC }\end{array}$ & NM_001003191 & 103 & 62 \\
\hline RPS5 & $\begin{array}{l}\text { TCA-CTG-GTG-AGA-ACC-CCC-T } \\
\text { CCT-GAT-TCA-CAC-GGC-GTA-G }\end{array}$ & XM_533568 & 141 & 62.5 \\
\hline$B 2 M G$ & $\begin{array}{l}\text { TCC-TCA-TCC-TCC-TCG-CT } \\
\text { TTC-TCT-GCT-GGG-TGT-CG }\end{array}$ & AB745507 & 85 & $61+63$ \\
\hline$S D H A$ & $\begin{array}{l}\text { GCC-TTG-GAT-CTC-TTG-ATG-GA } \\
\text { TTC-TTG-GCT-CTT-ATG-CGA-TG }\end{array}$ & DQ402985 & 92 & 61 \\
\hline
\end{tabular}

A proportional hazard model was used for analysis of gene expression of the surface markers. This model can provide an estimate of the treatment effect on gene expression levels, with the possibility to explore other explanatory variables. In the case of gene expression analysis by qPCR, the survival time is the number of qPCR cycles needed before the detection threshold is reached, also referred to as $\mathrm{C}_{\mathrm{q}}$ value. If the cDNA concentration in a sample is below the detection threshold, the sample is censored in the last time interval (at 45 cycles).

Possible independent variables associated with survival time were fixed variables: cell type, donor age, and passage number. Correlation between samples of the same donor was taken into account by adding a random donor effect to the model. To correct sample variation, $\mathrm{C}_{\mathrm{q}}$ values of the mean of the reference genes were added as a covariate. If the proportional hazard assumption was violated with noticeable deviations, models were optimized by using the $\mathrm{C}_{\mathrm{q}}$ value/reference gene $\mathrm{Ct}$ value ratio instead of incorporating the reference gene $\mathrm{C}_{\mathrm{q}}$ value as a covariate. Model selection was based on the lowest AIC. Regression coefficients (b) of the variable were estimated by the maximum likelihood method. Hazard ratios (eb) were considered significant if 1 was not included in the confidence interval. The model was corrected for multiple comparisons by adjusting the confidence interval for the number of comparisons.

Table 3. List of Antibodies Included in the FACS Analysis

\begin{tabular}{lllll}
\hline Target & Host & \multicolumn{1}{c}{ Reactivity } & \multicolumn{1}{c}{ Manufacturer } & Catalog number \\
\hline CD105 & Rabbit & Dog-Pig & Antibodies online & ABIN888668 \\
CD90 & Rat & Dog & eBioscience & $12-5900-42$ \\
CD29 & Mouse & Human-Cow-Dog & BioLegend & 303004 \\
CD166 & Rabbit & Human-Mouse-Rat-Cow- & Antibodies online & ABIN673954 \\
& & Dog-Pig-Horse-Chicken & LSBio & \\
CD45 & Rat & Dog & LS-C127720 \\
Rat IgGk & Rat & - & Antibodies online & AB-4031-82 \\
Rabbit IgGk & Rabbit & - & BioLegend & 400112 \\
Mouse IgGk & Mouse & - & &
\end{tabular}

FACS, fluorescent-activated cell sorting. 
A

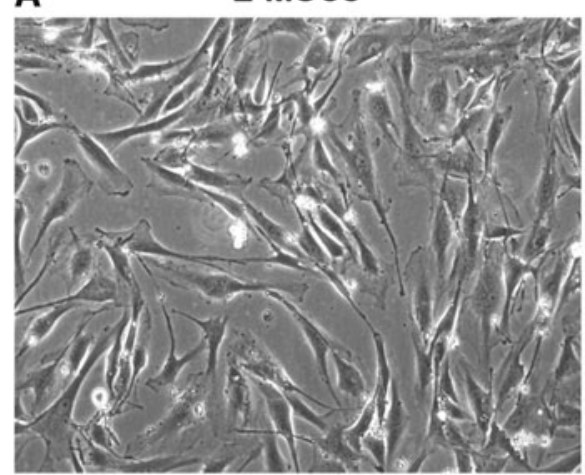

FIG. 1. Canine multipotent stromal cell morphology and proliferation rate. (A) Representative picture of liver-derived multipotent stromal cells (L-MSCs) and bone marrow-derived MSCs (BM-MSCs) with a spindle-shaped fibroblast-like morphology, passage 3. Original magnification $100 \times$. (B) Cumulative population doubling of L-MSCs (black dots, $n=10$ ) and BM-MSCs (white dots, $n=10$ ). The population doubling of the L-MSCs did not significantly differ compared to BM-MSCs and had an average population doubling per passage of $2.75 \pm 0.74$.

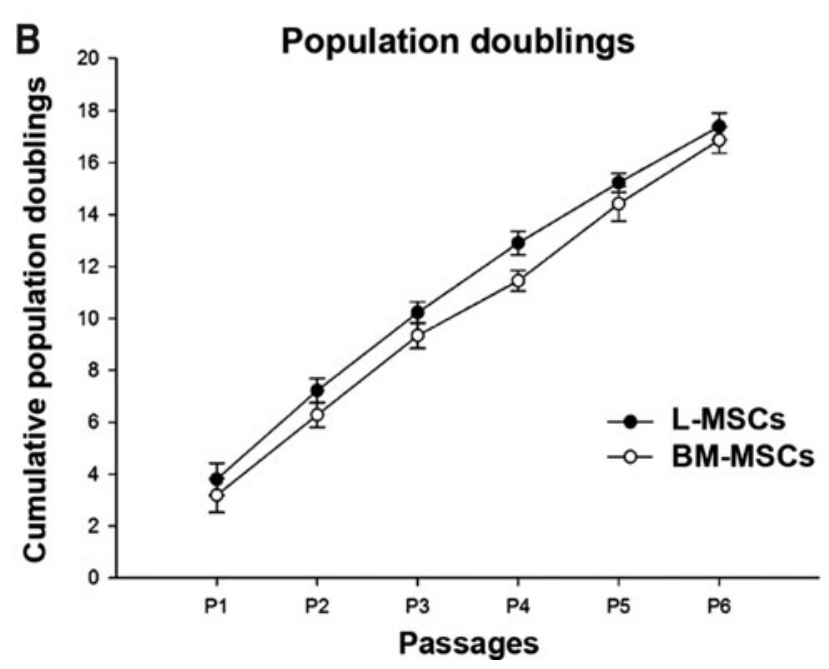

BM-MSCs

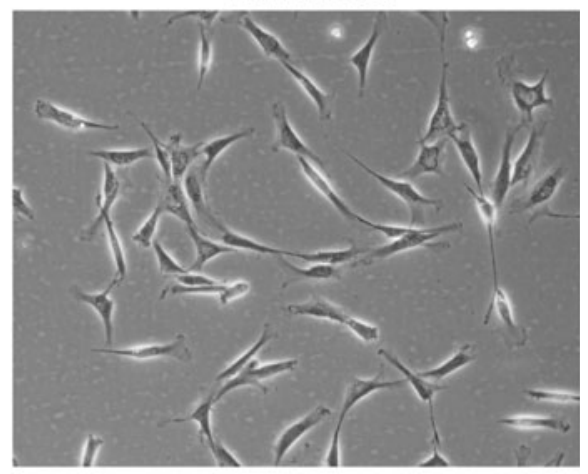




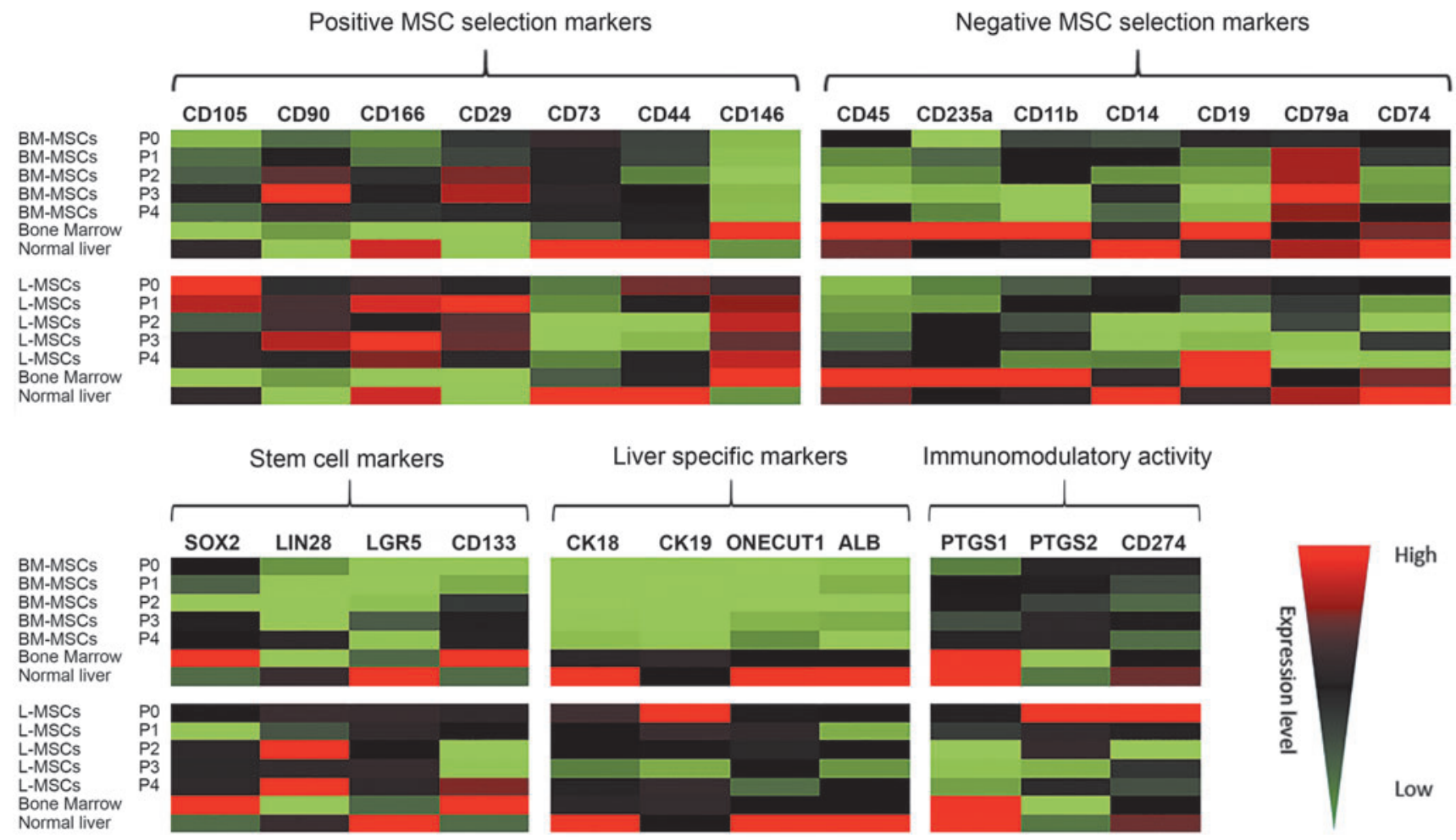

FIG. 2. Quantitative PCR (qPCR) on L-MSCs $(n=10)$ and BM-MSCs $(n=10)$ per passage. Heat map generated by qPCR analysis on genes, including positive and negative markers for MSC selection, liver-specific markers, stemness properties, and modulatory activity-associated markers. RNA derived from normal liver $(n=2)$ and crude bone marrow extracts $(n=3)$ was used as a control.

Furthermore, gene expression levels of BM-MSCs and L-MSCs were compared by qPCR analysis for a multitude of markers investigating gene expression differences based on positional imprinting, including liver-specific markers (CK18, CK19, ONECUT1, and $A L B$ ), stemness properties (SOX2, $L I N 28, L G R 5$, and $C D 133$ ), and modulatory activity-associated markers (PTGS-1, PTGS-2, and CD274). L-MSCs appear to retain a liver-specific imprinting by expression of markers such as $C K 18$ (hepatocyte marker) or CK19 (liver progenitor cell marker). Expression of these markers was detectable in L-MSCs but not BM-MSCs. Although the difference between the cell types remained significant during the different passages, passages 2 and 3 showed a significantly lower expression of $C K 18$ compared with passage 0. Expression of $A L B$ or ONECUTl was not detected in any of the groups.

Low levels of stem cell marker expression (SOX2, LIN28, $L G R 5$, and CD133) were detectable by qPCR for all markers that were included. When compared to positive control liver samples, expression of $L G R 5$ was minimally detectable in L-MSCs and absent in the bone marrow. In addition, embryonic stem cell markers (OCT4 and NANOG) were tested but were not detectable in both sample groups (data not shown). Finally, the expression of CD274 (PDL-1), PTGS-1, and $P T G S-2$ genes, involved in immunomodulatory prostaglandin production and signaling pathways, was not different between the different cell groups and passages.

\section{Cell differentiation assays}

L-MSCs and BM-MSCs were cultured, after expansion up to passage 2, in osteogenic, adipogenic, and chondrogenic differentiation medium.
Osteogenic differentiation. During osteoblast differentiation, cells gradually adapted a more round polygonal appearance and small nodules started appearing between 1 and 2 weeks, depending on the donor. After 21 days, Alizarin Red staining demonstrated mineral deposits characteristic for osteogenic differentiation. Large mineralized noduli were present in BM-MSCs, while L-MSC donors presented primarily a higher amount of small mineralized noduli (Fig. 3A).

For the analysis of gene expression, BM-MSCs and L-MSCs were each compared to their own control, as differences in basal expression of the osteogenic genes between the control groups were present; we observed a higher basal expression of the BM-MSC control group compared to the L-MSC control group. Osteocalcin (BGLAP), a late differentiation marker, was significantly upregulated in BMMSCs. Osteopontin (SPP1), which regulates formation and remodeling of mineralized tissue and is expressed during the osteoblast and osteocyte stages, was not significantly upregulated in the osteogenic group compared with the control group in both cell types. The relative fold change in the BMMSC group was higher compared with the L-MSC group, but no significant differences were found between the two cell types (Fig. 3B).

Adipogenic differentiation. Oil Red O staining was observed in all BM-MSC donor cells, indicating that these cells differentiated into the adipogenic lineage (Fig. 3A); however, variation in densities of lipid droplets was seen. In L-MSCs, adipogenic differentiation was only observed in one donor and in a very limited number of cells. One out of four donors seemed to undergo cell death. No significant differences were found in the gene expression of $A D I P O Q$, which is exclusively 

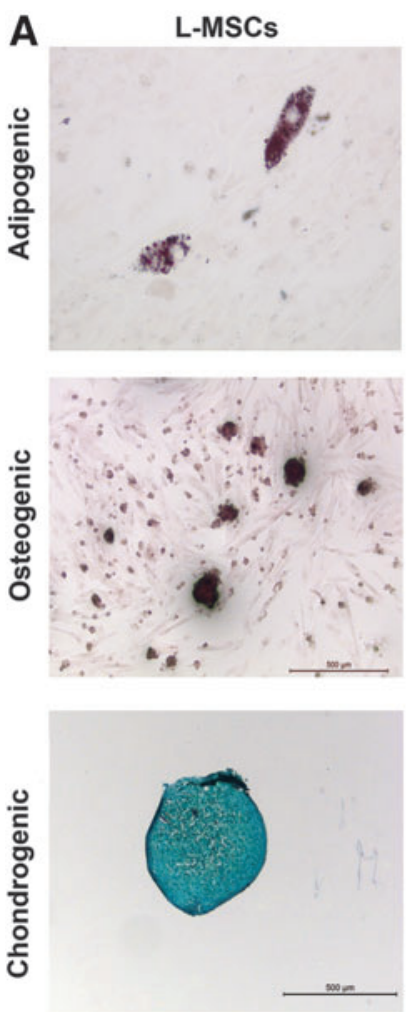
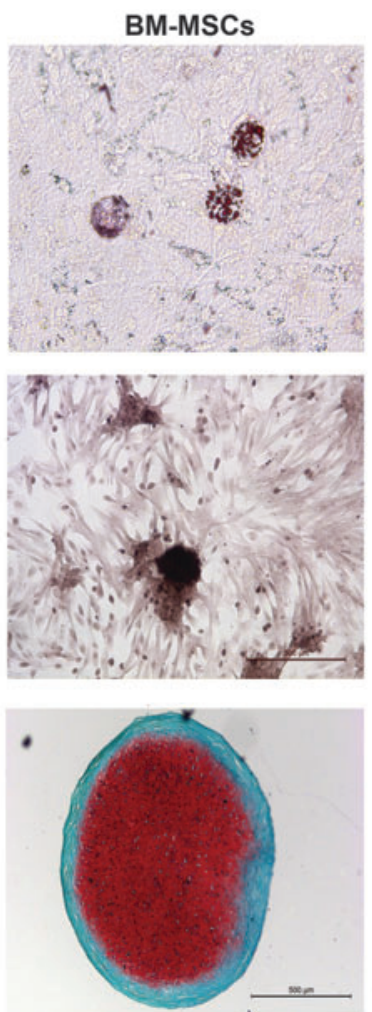
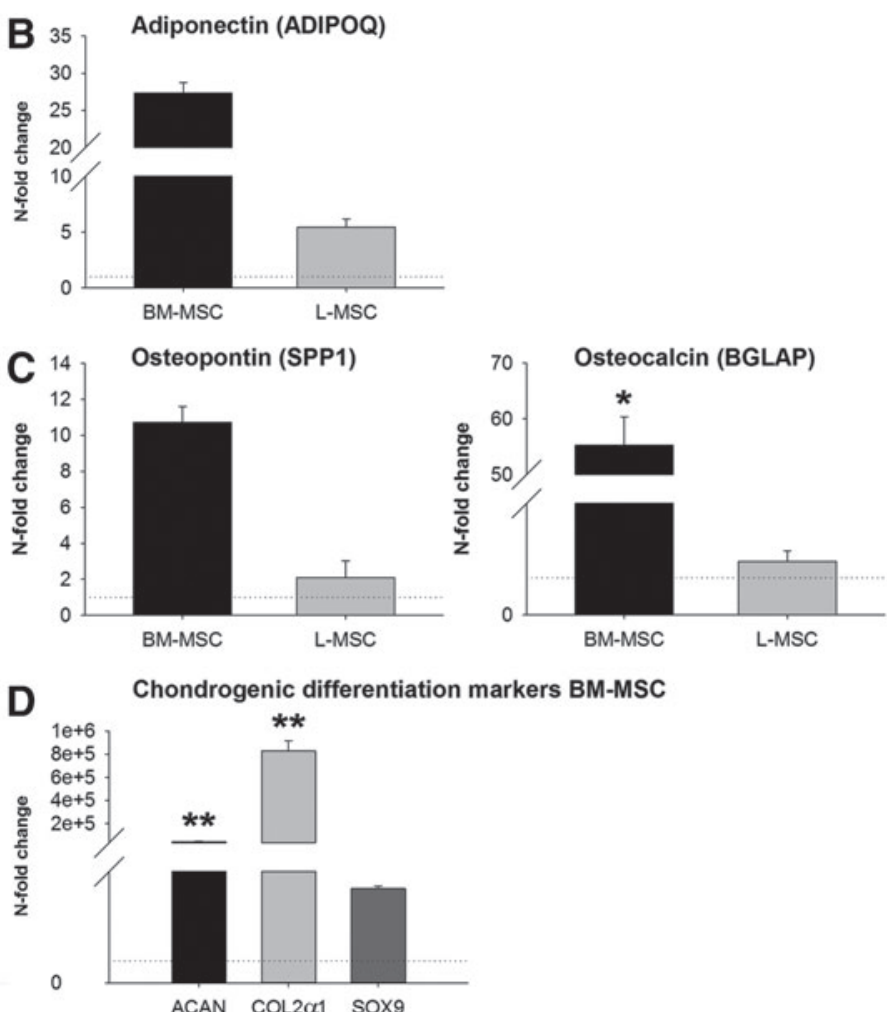

FIG. 3. Adipogenic, osteogenic, and chondrogenic differentiation of canine L-MSCs $(n=4)$ and BM-MSCs $(n=4)$. (A) Adipogenic differentiation (20× magnification) is visualized by Oil-red-O staining, staining the lipid droplets red. In the osteogenic differentiation ( $4 \times$ magnification), the mineralization noduli are stained with Alizarin red. Chondrogenic differentiation ( $4 \times$ magnification) is only achieved in the BM-MSCs as visualized by a positive Safranin-O (red) staining. Scale bar $=500 \mu \mathrm{m}$. Relative gene expression of genes related to adipogenic (B), osteogenic (C), and chondrogenic (D) differentiation, where the undifferentiated controls of each cell type were set at 1 (indicated by the dotted baseline). $* P<0.05 ; * * P<0.01$ indicates significant difference from the undifferentiated control.

expressed in and excreted by adipose tissue, although a trend toward upregulation was seen for the adipogenic compared to the control group in the BM-MSCs (Fig. 3B).

Chondrogenic differentiation. All BM-MSC donors were cultured with TGF- $\beta 1$ differentiated toward the chondrogenic lineage as shown by Safranin-O/Fast Green staining (Fig. 3A). In addition, chondrocyte-like cells were present in the pellet. Chondrogenic differentiation was not observed in either the control or L-MSC pellets (Fig. 3A), not even in the presence of TGF- $\beta 1$ and BMP- 2 . We identified small pycnotic cells in the center of these pellets, indicating cell death. Chondrogenic differentiation was assessed by gene expression analysis of ACAN, COL $2 \alpha 1$, SOX9, and COLX. SOX9 is the earliest chondrocyte marker and a necessary transcription factor for chondrocyte proliferation. Activation of SOX9 leads to activation of other early chondrocyte differentiation markers, such as COL $2 \alpha 1$ and ACAN, both cartilage matrix components. In BM-MSCs, both ACAN and COL $2 \alpha 1$ were upregulated in the TGF- $\beta 1$ group compared to undifferentiated MSCs (control) (Fig. 3B). In LMSCs, no expression of the chondrogenic differentiation markers was observed, regardless of the conditions (TGF- $\beta 1$ alone or TGF- $\beta 1$ and BMP-2). Expression of COLX, a late chondrocyte differentiation marker mainly found in the hypertrophic phase of chondrogenic differentiation, was not detected in both cell types.

\section{Fluorescent-activated cell sorting}

L-MSCs and BM-MSCs expressed CD105, CD90, CD166, and CD29 and were negative for CD45 (Fig. 4 and Table 4). There were no significant differences between L-MSCs and BM-MSCs, indicating that there were no differences in the MSC surface marker expression.

\section{Discussion}

Characterization of canine L-MSCs and BM-MSCs, following the minimal criteria proposed by the ISCT [23], demonstrated that the two cell types were highly comparable with the exception of the differentiation potential of the two groups. No significant difference was found in the cell growth rate between L-MSCs and BM-MSCs, and the populations displayed similar in vitro morphology. Moreover, gene expression profiling in both MSC populations demonstrated the presence of the MSC-positive surface markers (CD105, CD90,CD166, CD29, and CD44) and absence of the negative surface markers (CD45, CD235s, $C D 11 b, C D 14, C D 19$, and CD74). These findings were, in part, confirmed by FACS analysis with canine-specific antibodies and isotype-negative controls.

Interestingly, expression of liver-specific markers, $C K 18$ and $C K 19$, was significantly higher in L-MSCs compared with BM-MSCs. This could indicate that while both cell 

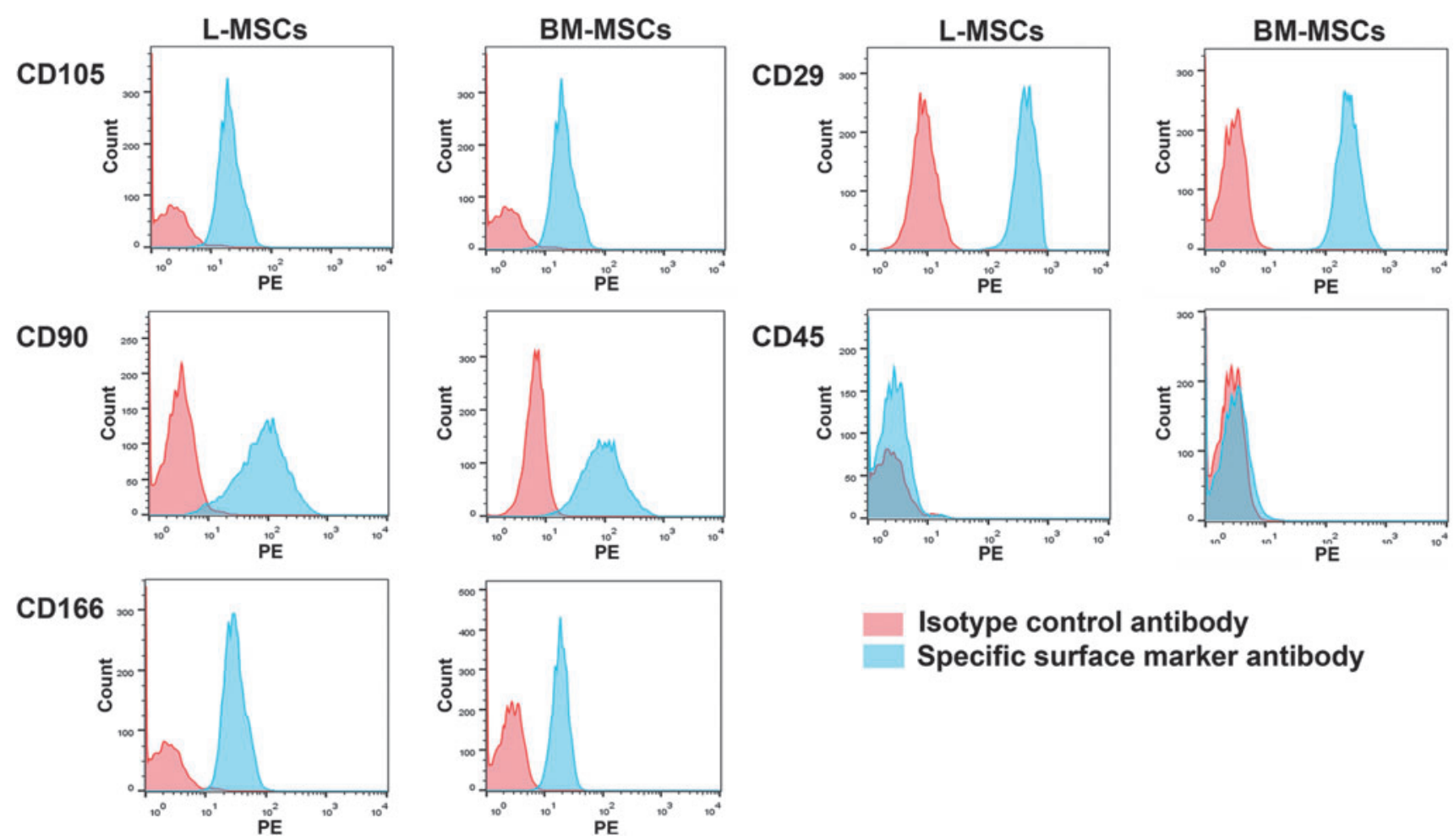

\section{Isotype control antibody Specific surface marker antibody}

FIG. 4. Representative examples of fluorescent-activated cell sorting (FACS) of canine L-MSCs $(n=8)$ and BM-MSCs $(n=6)$. Flow cytometry analysis of surface markers showed that the expanded cells exhibited a typical MSC-like phenotype positive for CD105, CD90, CD166, and CD29, and they were mostly negative for the leukocyte lineage markers CD45. There was no difference between L-MSCs and BM-MSCs. The blue histograms represent the specific staining, and the red histograms indicate background staining of an isotype-matched control antibody.

populations possess MSC features, such as morphology and surface marker expression, characteristics of the tissue of origin remain. This, in turn, could explain the differences in differentiation potential between the cell types. In comparison to L-MSCs, BM-MSCs differentiated into the chondrogenic lineage (L-MSCs failed) and presented a more intense staining for lipid droplets during adipogenic differentiation, as well as a higher expression level of bonerelated genes. This difference in differentiation potential is a common finding in studies that compared different populations of MSCs in dogs [30] as well as in humans [31]. Different growth factors may be required to induce chondrogenic differentiation of MSCs depending on tissue source, a phenomenon probably dependent on the stem cell niche [32]. Although many studies showed a positive role of
MSCs in the regeneration of cirrhotic liver [33], other studies indicated that MSCs could also differentiate toward myofibroblasts and significantly contribute to liver fibrosis [34]. Since L-MSCs still express liver progenitor (CK19) and hepatocyte-specific ( $C K 18)$ genes, it remains to be seen if these cells are superior for the treatment of liver diseases since they are less prone to differentiate toward myofibroblasts.

In addition to the differentiation capability toward the three lineages, some differences were found in the expression of the pluripotency markers. More specifically, L-MSCs and BM-MSCs were negative for SOX2 and LIN28, which contrast with earlier findings that demonstrated expression of SOX2, NANOG, and Oct4 (pluripotency markers) in canine and human BM-MSCs $[2,35]$. Interestingly,

Table 4. Percentage Positive Canine L-MSCs or BM-MSCs Analyzed by FACS

\begin{tabular}{lcccc}
\hline & \multicolumn{2}{c}{ L-MSC } & & \multicolumn{2}{c}{ BM-MSC } \\
\cline { 2 - 3 } & $\begin{array}{c}\text { Mean } \\
\text { (\% of positive cells) }\end{array}$ & $\begin{array}{c}\text { 95\% } \\
\text { confidence interval }\end{array}$ & (\% of positive cells) & $\begin{array}{c}\text { M5\% } \\
\text { confidence interval }\end{array}$ \\
\hline CD105 & 51.8 & $20.8-82.7$ & 63.6 & $38.7-88.6$ \\
CD90 & 58.2 & $37.7-78.8$ & 67.9 & $42.9-92.8$ \\
CD166 & 74.9 & $45.8-104.0$ & 71.3 & $38.7-103.9$ \\
CD45 & 98.6 & $96.7-100.5$ & 99.8 & $99.6-100$ \\
\hline
\end{tabular}

BM-MSCs, bone marrow-derived multipotent stromal cells; L-MSCs, liver-derived MSCs. 
we did observe expression of the stem cell marker, $L G R 5$, in L-MSCs but not in the BM-MSCs. This may indicate a higher stemness potential of L-MSCs and could also indicate a potential influence of the MSC niche since LGR5positive cells are only identified in a limited number of tissues in the adult animal [36]. Based on this, we suggest that L-MSCs may be a potential source for the generation of liver organoids [37].

It is thought that MSCs contribute to tissue regeneration either directly, by repopulation of the injured site, or indirectly, by secreting molecules that alter the tissue microenvironment and stimulate regeneration. The high potential of MSCs to differentiate in vitro into various cell lineages supports the repopulation theory. However, previous studies report that the therapeutic efficacy often does not correlate with MSC engraftment efficiency. This suggests that the therapeutic efficacy is mainly determined by the indirect (paracrine) effect of MSCs and to a lesser extent through transdifferentiation of MSCs into the appropriate cell phenotype [38]. This includes L-MSCs, which have been shown to secrete factors that promote liver regeneration after partial hepatectomy [39]. Recently, the paracrine activity of MSCs has evoked an increased interest due to their immunomodulatory properties [40]. Clinical trials are already exploring these properties, including the paracrine and endocrine regulation of inflammatory responses in the patient [41]. We studied the immunomodulation effect of L-MSCs and BM-MSCs by gene expression profiling. Genes involved in the prostaglandin synthesis and its subsequent signaling pathway [CD274 (PDL-1) and PTGS-2 (COX-2)] were present in both L-MSCs and BM-MSCs, supporting the theory that MSCs exert an immunomodulatory effect.

The exact identity of MSCs is still unclear. A primary limitation of this and other studies is the fact that MSC cultures are established by the ability of these cells to adhere to culture plastics and by nature are heterogeneous populations [42]. Culturing the progeny of a single CFU or phenotypeisolated single clonogenic cell [42] would give rise to a more homogenous "true" MSC population that can be better characterized and provide consistent results in clinical applications. By selecting human MSCs (hMSCs) with a combination of three cell surface markers (LNGFR, THY-1, and VCAM-1), Mabuchi et al. demonstrated a functionally distinct population of hMSCs that exhibited robust multilineage differentiation and self-renewal potency [43], supporting the previous theory. Recently, Crisan [44] isolated a population of perivascular cells (pericytes) from different tissues among the body; this cell population expresses all the common MSC markers and is able to differentiate into the three lineages recapitulating a true mesenchymal cell phenotype. In the present study, we discovered that only L-MSCs express CD146 (Fig. 2), a common pericyte marker. This is intriguingly reinforced by Bianco et al. [42] who suggested that CD146 can be used to distinguish between MSCs derived from bone marrow or other sources. This finding also gives strength to the idea that MSCs from highly vascularized tissues might come from a mesodermal vascular progenitor shared with pericytes.

MSCs may have an advantage in the clinic (eg, in allogeneic cell transplantation therapies); they are easily accessible and possess both multilineage differentiation potential and immunomodulatory effects. Our study re- ported (very) low gene expression of MHC-II (CD73 or HLA-DR) in both cell populations.

In this study, the PD time, surface marker expression, differentiation potential, and immunomodulatory effects of canine L-MSCs were investigated and compared to BM-MSCs of the same individual. Although the two cell populations seemed very similar in general, differences in differentiation potential and the gene expression of liver-associated markers and the stemness marker, LGR5, were observed. This could indicate a difference in the nature of different MSC populations caused by influence of the tissue of origin or heterogeneity of MSC cultures. It is still unknown which cell source is preferable for application in liver regenerative strategies; however, this study does provide the basis for controlled studies with MSC therapy on various liver diseases in dogs before their application in man.

\section{Acknowledgments}

The authors thank the pathologist Guy Grinwis (pathobiology, Utrecht University, the Netherlands) for his assessment of the liver tissue samples and Hans Vernooij (Utrecht University Center for Biostatistics) for his assistance on the statistics. This work was sponsored by the Dutch Research Counsel NWO/ZonMW (grant-number 116004121).

\section{Author Disclosure Statement}

No competing financial interests exist.

\section{References}

1. Horwitz E, K Le Blanc, M Dominici, I Mueller, I SlaperCortenbach, F Marini, R Deans, D Krause and A Keating. (2005). Clarification of the nomenclature for MSC: the International Society for Cellular Therapy position statement. Cytotherapy 7:393-395.

2. Kisiel AH, LA McDuffee, E Masaoud, TR Bailey, BP Esparza Gonzalez and R Nino-Fong. (2012). Isolation, characterization, and in vitro proliferation of canine mesenchymal stem cells derived from bone marrow, adipose tissue, muscle, and periosteum. Am J Vet Res 73:1305-1317.

3. Ong WK and S Sugii. (2013). Adipose-derived stem cells: fatty potentials for therapy. Int J Biochem Cell Biol 45:1083-1086.

4. Jankowski RJ, BM Deasy and J Huard. (2002). Musclederived stem cells. Gene Ther 9:642-647.

5. Gage FH, PW Coates, TD Palmer, HG Kuhn, LJ Fisher, JO Suhonen, DA Peterson, ST Suhr and J Ray. (1995). Survival and differentiation of adult neuronal progenitor cells transplanted to the adult brain. Proc Natl Acad Sci U S A 92:11879-11883.

6. Pan Q, SM Fouraschen, FS Kaya, MM Verstegen, M Pescatori, AP Stubbs, W van IJcken, A Van Der Sloot, R Smits and J Kwekkeboom. (2011). Mobilization of hepatic mesenchymal stem cells from human liver grafts. Liver Transpl 17:596-609.

7. Meirelles LdS, PC Chagastelles and NB Nardi. (2006). Mesenchymal stem cells reside in virtually all post-natal organs and tissues. J Cell Sci 119:2204-2213.

8. Kuo TK, S Hung, C Chuang, C Chen, YV Shih, SY Fang, VW Yang and OK Lee. (2008). Stem cell therapy for liver disease: parameters governing the success of using bone marrow mesenchymal stem cells. Gastroenterology 134:2111-2121, 2121.e1-3. 
9. Kim W, J Smith, M Skeans, D Schladt, M Schnitzler, E Edwards, A Harper, J Wainright, J Snyder and A Israni. (2014). OPTN/SRTR 2012 annual data report: liver. Am J Transplant 14:69-96.

10. Shi M, Z Zhang, R Xu, H Lin, J Fu, Z Zou, A Zhang, J Shi, L Chen, et al. (2012). Human mesenchymal stem cell transfusion is safe and improves liver function in acute-on-chronic liver failure patients. Stem Cells Transl Med 1:725-731.

11. Terai S, T Takami, N Yamamoto, K Fujisawa, T Ishikawa, $\mathrm{Y}$ Urata, $\mathrm{H}$ Tanimoto, $\mathrm{T}$ Iwamoto, $\mathrm{Y}$ Mizunaga and $\mathrm{T}$ Matsuda. (2014). Status and prospects of liver cirrhosis treatment by using bone marrow-derived cells and mesenchymal cells. Tissue Eng Part B Rev 20:206-210.

12. Reinders ME, WE Fibbe and TJ Rabelink. (2010). Multipotent mesenchymal stromal cell therapy in renal disease and kidney transplantation. Nephrol Dial Transplant 25:17-24.

13. Uccelli A, L Moretta and V Pistoia. (2008). Mesenchymal stem cells in health and disease. Nat Rev Immunol 8:726-736.

14. van Poll D, B Parekkadan, $\mathrm{CH}$ Cho, F Berthiaume, $\mathrm{Y}$ Nahmias, AW Tilles and ML Yarmush. (2008). Mesenchymal stem cell-derived molecules directly modulate hepatocellular death and regeneration in vitro and in vivo. Hepatology 47:1634-1643.

15. Parekkadan B, D Van Poll, K Suganuma, EA Carter, F Berthiaume, AW Tilles and ML Yarmush. (2007). Mesenchymal stem cell-derived molecules reverse fulminant hepatic failure. PLoS One 2:e941.

16. Neff MW and J Rine. (2006). A fetching model organism. Cell 124:229-231.

17. Schotanus BA, TS van den Ingh, LC Penning, J Rothuizen, TA Roskams and B Spee. (2009). Cross-species immunohistochemical investigation of the activation of the liver progenitor cell niche in different types of liver disease. Liver Int 29:1241-1252.

18. Kruitwagen H, B Spee and B Schotanus. (2014). Hepatic progenitor cells in canine and feline medicine: potential for regenerative strategies. BMC Vet Res 10:137.

19. Schotanus BA, LC Penning and B Spee. (2013). Potential of regenerative medicine techniques in canine hepatology. Vet Q 33:207-216.

20. Rouger K, T Larcher, L Dubreil, J Deschamps, C Le Guiner, G Jouvion, B Delorme, B Lieubeau, M Carlus and B Fornasari. (2011). Systemic delivery of allogenic muscle stem cells induces long-term muscle repair and clinical efficacy in duchenne muscular dystrophy dogs. Am J Pathol 179:2501-2518.

21. Pan X, Y Yue, K Zhang, W Lostal, J Shin and D Duan. (2013). Long-term robust myocardial transduction of the dog heart from a peripheral vein by adeno-associated virus serotype-8. Hum Gene Ther 24:584-594.

22. Sampaolesi M, S Blot, G D'antona, N Granger, R Tonlorenzi, A Innocenzi, P Mognol, J Thibaud, BG Galvez and I Barthélémy. (2006). Mesoangioblast stem cells ameliorate muscle function in dystrophic dogs. Nature 444:574-579.

23. Dominici M, K Le Blanc, I Mueller, I Slaper-Cortenbach, FC Marini, DS Krause, RJ Deans, A Keating, DJ Prockop and EM Horwitz. (2006). Minimal criteria for defining multipotent mesenchymal stromal cells. The International Society for Cellular Therapy position statement. Cytotherapy 8:315-317.

24. Wagner W, P Horn, M Castoldi, A Diehlmann, S Bork, R Saffrich, V Benes, J Blake, S Pfister, V Eckstein and AD Ho. (2008). Replicative senescence of mesenchymal stem cells: a continuous and organized process. PLoS One 3:e2213.
25. Zuker M. (2003). Mfold web server for nucleic acid folding and hybridization prediction. Nucleic Acids Res 31:3406-3415.

26. Brinkhof B, B Spee, J Rothuizen and LC Penning. (2006). Development and evaluation of canine reference genes for accurate quantification of gene expression. Anal Biochem 356:36-43.

27. Vandesompele J, K De Preter, F Pattyn, B Poppe, N Van Roy, A De Paepe and F Speleman. (2002). Accurate normalization of real-time quantitative RT-PCR data by geometric averaging of multiple internal control genes. Genome Biol 3:RESEARCH0034.

28. Vieira N, V Brandalise, E Zucconi, M Secco, B Strauss and M Zatz. (2010). Isolation, characterization, and differentiation potential of canine adipose-derived stem cells. Cell Transplant 19:279-289.

29. de Bakker E, B Van Ryssen, C De Schauwer and E Meyer. (2013). Canine mesenchymal stem cells: state of the art, perspectives as therapy for dogs and as a model for man. Vet Q 33:225-233.

30. Ock S, G Maeng, Y Lee, T Kim, BM Kumar, S Lee and G Rho. (2013). Donor-matched functional and molecular characterization of canine mesenchymal stem cells derived from different origins. Cell Transplant 22:2311-2321.

31. Musina R, E Bekchanova, A Belyavskii and G Sukhikh. (2006). Differentiation potential of mesenchymal stem cells of different origin. Bull Exp Biol Med 141:147-151.

32. Boeuf S and W Richter. (2010). Chondrogenesis of mesenchymal stem cells: role of tissue source and inducing factors. Stem Cell Res Ther 1:31.

33. Mohamadnejad M, K Alimoghaddam, M Bagheri, M Ashrafi, L Abdollahzadeh, S Akhlaghpoor, M Bashtar, A Ghavamzadeh and R Malekzadeh. (2013). Randomized placebo-controlled trial of mesenchymal stem cell transplantation in decompensated cirrhosis. Liver Int 33:14901496.

34. Li C, Y Kong, H Wang, S Wang, H Yu, X Liu, L Yang, X Jiang, L Li and L Li. (2009). Homing of bone marrow mesenchymal stem cells mediated by sphingosine 1-phosphate contributes to liver fibrosis. J Hepatol 50:1174-1183.

35. Izadpanah R, C Trygg, B Patel, C Kriedt, J Dufour, JM Gimble and BA Bunnell. (2006). Biologic properties of mesenchymal stem cells derived from bone marrow and adipose tissue. J Cell Biochem 99:1285-1297.

36. Barker N, JH van Es, J Kuipers, P Kujala, M van den Born, M Cozijnsen, A Haegebarth, J Korving, H Begthel and PJ Peters. (2007). Identification of stem cells in small intestine and colon by marker gene Lgr5. Nature 449:1003-1007.

37. Huch M, C Dorrell, SF Boj, JH van Es, VS Li, M van de Wetering, T Sato, K Hamer, N Sasaki and MJ Finegold. (2013). In vitro expansion of single Lgr5 liver stem cells induced by Wnt-driven regeneration. Nature 494:247-250.

38. Phinney DG and DJ Prockop. (2007). Concise review: mesenchymal stem/multipotent stromal cells: the state of transdifferentiation and modes of tissue repair-current views. Stem Cells 25:2896-2902.

39. Fouraschen SM, Q Pan, PE de Ruiter, WR Farid, G Kazemier, J Kwekkeboom, JN Ijzermans, HJ Metselaar, HW Tilanus and J de Jonge. (2012). Secreted factors of human liver-derived mesenchymal stem cells promote liver regeneration early after partial hepatectomy. Stem Cells Dev 21:2410-2419.

40. Spaggiari GM and L Moretta. (2012). Cellular and molecular interactions of mesenchymal stem cells in innate immunity. Immunol Cell Biol 91:27-31. 
41. Ankrum J and JM Karp. (2010). Mesenchymal stem cell therapy: two steps forward, one step back. Trends Mol Med 16:203-209.

42. Bianco P, X Cao, PS Frenette, JJ Mao, PG Robey, PJ Simmons and C Wang. (2013). The meaning, the sense and the significance: translating the science of mesenchymal stem cells into medicine. Nat Med 19:35-42.

43. Mabuchi Y, S Morikawa, S Harada, K Niibe, S Suzuki, F Renault-Mihara, DD Houlihan, C Akazawa, H Okano and Y Matsuzaki. (2013). LNGFR ${ }^{+}$THY $-1^{+}$VCAM- $1^{\text {hi }+}$ cells reveal functionally distinct subpopulations in mesenchymal stem cells. Stem Cell Reports 1:152-165.

44. Crisan M. (2013). Transition of mesenchymal stem/stromal cells to endothelial cells. Stem Cell Res Ther 4:1-3.
Address correspondence to:

Dr. Bart Spee

Department of Clinical Sciences of Companion Animals Faculty of Veterinary Medicine Utrecht University Yalelaan 104 3584 CM Utrecht The Netherlands

E-mail: b.spee@uu.nl

Received for publication April 1, 2015 Accepted after revision October 12, 2015

Prepublished on Liebert Instant Online October 14, 2015 